\title{
Review \\ Hydrogen Technology, a short Overview
}

\author{
Alexander Charitos $1, \$$ and Sofoklis Makridis $1, \$$
}

1 Department of Environmental Engineering, University of Patras,

GR30100 Agrinio, Greece; smakridis@upatras.gr

$\$$ These authors contributed equally to this work.

\begin{abstract}
1 Abstract: The Residential and Industrial zones as is, rely heavily, if not exclusively, on Hydrocarbons. Hydrocarbon thermal machinery such as Spark Ignition-Compression Ignition engines, Gasoline-Diesel generators, Coal-Lignite gasifiers, residential diesel-powered heating systems, Pyrolysis units and so on, are commonly met all around the planet. Such technology practically oxidizes Hydrocarbons to produce either heat, steam or useful mechanical work depending on the application, though energy losses are not, by any means, insignificant. Advanced material processing is an industrial sector who's energy demand is significant and it is important for the general public to come to terms with the fact that by implementing Hydrogen technology to power such plant while at the same time improving the energy equilibrium of houses(advanced materials), communities would be taking major steps towards Climate Change effects debilitation. The downside of Hydrocarbon thermochemical exploitation can be described by the limited resources-reserves and the gaseous pollutant emissions $\left(\mathrm{CO}_{2}, \mathrm{CO}, \mathrm{NO}_{\mathrm{x}}, \mathrm{SO}_{\mathrm{x}}\right)$. In recent years, the Industrial zone as a whole has began taking a turn towards Electrification without having established the necessary infrastructure to support such a transition. Indicatively, at current rate of production, dead Lithium-Ion batteries are projected to reach as high as 11,000 metric tons by 2030, yet there is no recycling scheme in place, not to mention the prospect of that number rising even more, given the recent e-mobility trend. As it pertains to Electrification, such powertrains-machinery require electricity and a battery. Electricity production is mainly achieved through Coal-Lignite gasification, Batteries require metals, among others, for manufacturing, meaning that up-on mining, local water resources are contaminated, another very important 'aspect' of Lithium(per say) mining is that child labor is often associated with such processes, a truly despicable act. All of the above paint a crystal-clear picture as to how 'environmentally friendly' reckless-rushed Electrification really is. Climate Change is up-on us and it's effects on the planet are obvious, the most important of which is glacier melting due to rising of the global Temperature. The COVID-19 crisis is a sign of what could come from glacier melting could as ice contains potentially harmfultoxic to humans, biological entities that are sure to be introduced to the general public if we were to continue exploiting mineral resources. Purpose of this paper is to provide a general overview of the technology around Hydrogen.
\end{abstract}

${ }_{9}$ Keywords: hydrogen, climate change, emissions, production, storage, utilization, energy, technology 


\section{Introduction}

Hydrogen has an important role to play in today's Linear Economy, indicatively, the Petrochemical, Pharmaceutical and Food industries utilize it in various processes as shown below,
* Hydrocarbon (crude oil) cracking
* Hydrocarbon-powered Ammonia Production
* Electromechanical equipment cooling agent
* Methanol Production
* Hydrogen Peroxide (sterilizing agent) production
* Reducing agent (Petrochemical Industry indicatively
* Carrier Gas for G.C. (Gas Chromatography) \{as opposed to N2 or He\}
* Saturizing agent (Benzane Hydrogenation indicatively)

Hydrogen can be further utilized in order to fuel a Circular Energy Economy as it is abundant beyond measure (approximately 75\% of all matter in the universe) and carbon free regarding it's stereochemical-molecular structure. It is important though to view Hydrogen not as a fuel but as an Energy carrier[Image 2-Image 3] for the replacement of conventional Energy carriers like Batteries. As shown below, Hydrogen makes for an excellent energy carrier as compared to any other existing alternatives.

\begin{tabular}{|c|c|c|}
\hline Quantity & Value & Units \\
\hline Mr(Molecular & 2.01594 & $\mathrm{~g} / \mathrm{mol}$ \\
\hline Liquid phase density & 70.8 & $\mathrm{~kg} / \mathrm{m}^{3}$ \\
\hline Self-ignition Temperature & 858 & K \\
\hline Viscosity & 8.75 & $\operatorname{Pa}^{*}$ (S.I. Units) \\
\hline Critical Temperature & 32.94 & K \\
\hline Critical Pressure & $1.284^{*} 10^{6}$ & $\mathrm{~Pa}$ \\
\hline Critical Density & 31.4 & $\mathrm{~kg} / \mathrm{m}^{3}$ \\
\hline $\begin{array}{l}\text { Minimum Heat-Production } \\
\text { Energy }\end{array}$ & $10.05 * 10^{3}$ & $\mathrm{~J} / \mathrm{m}^{3}$ \\
\hline $\begin{array}{l}\text { Maximum Heat-Production } \\
\text { Energy }\end{array}$ & $11.89 * 10^{3}$ & $\mathrm{~J} / \mathrm{m}^{3}$ \\
\hline Maximum Flame Temperature & 2403 & K \\
\hline Diffusion Coefficient & 0.61 & $\mathrm{~m}^{2} / \mathrm{s}$ \\
\hline
\end{tabular}

Figure 1 : Chemical properties of Hydrogen 


\begin{tabular}{|c|c|c|}
\hline Energy Carrier & Specific Energy Density & Units \\
\hline Hydrogen & 142 & $\mathrm{MJ} / \mathrm{Kg}$ \\
\hline Lithium-Ion Battery & 0.6 & $\mathrm{MJ} / \mathrm{Kg}$ \\
\hline Nickel Cadmium Battery & $0.144-0.216$ & $\mathrm{MJ} / \mathrm{Kg}$ \\
\hline $\begin{array}{l}\text { Nickel Metal Hydride } \\
\text { Battery }\end{array}$ & $0.36-0.436$ & $\mathrm{MJ} / \mathrm{Kg}$ \\
\hline Lead Acid Battery & $0.126-0.144$ & $\mathrm{MJ} / \mathrm{Kg}$ \\
\hline $\begin{array}{l}\text { Lithium lon Polymer } \\
\text { Battery }\end{array}$ & $0.36-0.95$ & $\mathrm{MJ} / \mathrm{Kg}$ \\
\hline
\end{tabular}

Figure 2 : SED comparison between Hydrogen and Batteries

\begin{tabular}{|c|c|c|}
\hline Energy Carrier & State & $\begin{array}{l}\text { (Specific Energy } \\
\text { Density) (J/kg) }\end{array}$ \\
\hline Ethanol & Liquid & $26.8^{*} 10^{6}$ \\
\hline Gasoline & Liquid & $44.4^{*} 10^{6}$ \\
\hline $\begin{array}{l}\text { Automotive Diesel } \\
\text { fuel }\end{array}$ & Liquid & $45.5^{*} 10^{6}$ \\
\hline Bio-Diesel fuel & Liquid & $37.27 * 10^{6}$ \\
\hline Hydrogen & Liquid & $141.86 * 10^{6}$ \\
\hline
\end{tabular}

Figure 3 : SED comparison between Hydrogen and Hydrocarbon fuel

\section{Hydrogen production}

Hydrogen can be produced through various processes[1], most of today's hydrogen production comes from fossil fuel processing, namely Coal Gasification, Methane Steam Reforming and Petroleum fraction partial Oxidation. Hydrogen produced by these processes is classified as 'Grey'[2] due to the gaseous pollutant emissions[4] although it is important to note that if Carbon Capture and Storage technology were to be implemented, then the produced Hydrogen would be classified as 'Blue'[3]. 'Green' Hydrogen[2] can only come through a process that, in all aspects, is zero-emission, the most well known system that can produce it is an R.E.S. powered Electrolysis module. 


\section{BLUE HYDROGEN}

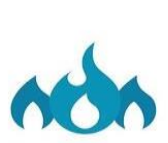

NATURAL GAS

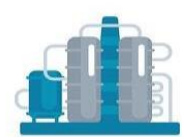

STEAM

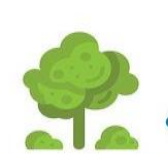

$\mathrm{CO}_{2}$ MANAGEMENT

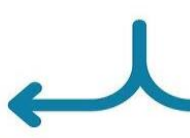

\section{GREEN HYDROGEN}

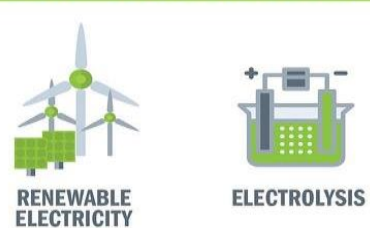

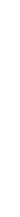
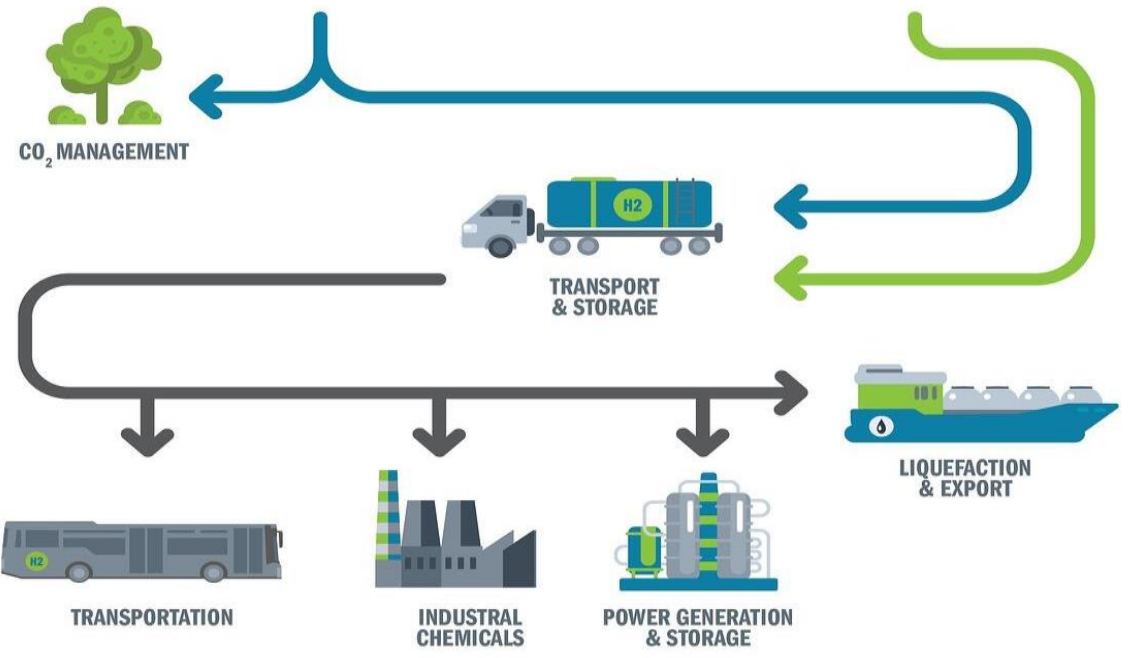

Figure 4 : Representation of the Hydrogen Colors, Source: ballard.com

Hydrogen can be produced through various processes[1], most of today's hydrogen production comes from fossil fuel processing, namely Coal Gasification, Methane Steam Reforming and Petroleum fraction partial Oxidation. Hydrogen produced by these processes is classified as 'Grey'[2] due to the gaseous pollutant emissions[1] although it is important to note that if Carbon Capture and Storage technology were to be implemented, then the produced Hydrogen would be classified as 'Blue'[3].

'Green' Hydrogen[2] can only come through a process that, in all aspects, is zero-emission, the most well known system that can produce it is an R.E.S. powered Electrolysis module.

\subsection{Methane $\left(\mathrm{CH}_{4}\right)$ Steam Reforming}

M.S.R. is a thermochemical process, during which methane molecules react with water in the form of steam at temperatures, often above 1073,3 K in order to produce hydrogen gas, followed by another stage at which the produced carbon monoxide reacts with water in the form of steam to produce carbon dioxide and hydrogen gas (again). This process accounts for $48 \%$ of the total amount of hydrogen produced per year, but given hydrocarbon deposits are declining it is imperative to limit this percentage as, given the technological evolution of electrolysis units, it would be counterproductive to consume an existing fuel (CH4, LNG as a compressed gas Fuel for internal combustion engines) while producing Carbon Dioxide in the process. Clean hydrogen production[1] is essential if at any point we strive for a Carbon-free industry. 


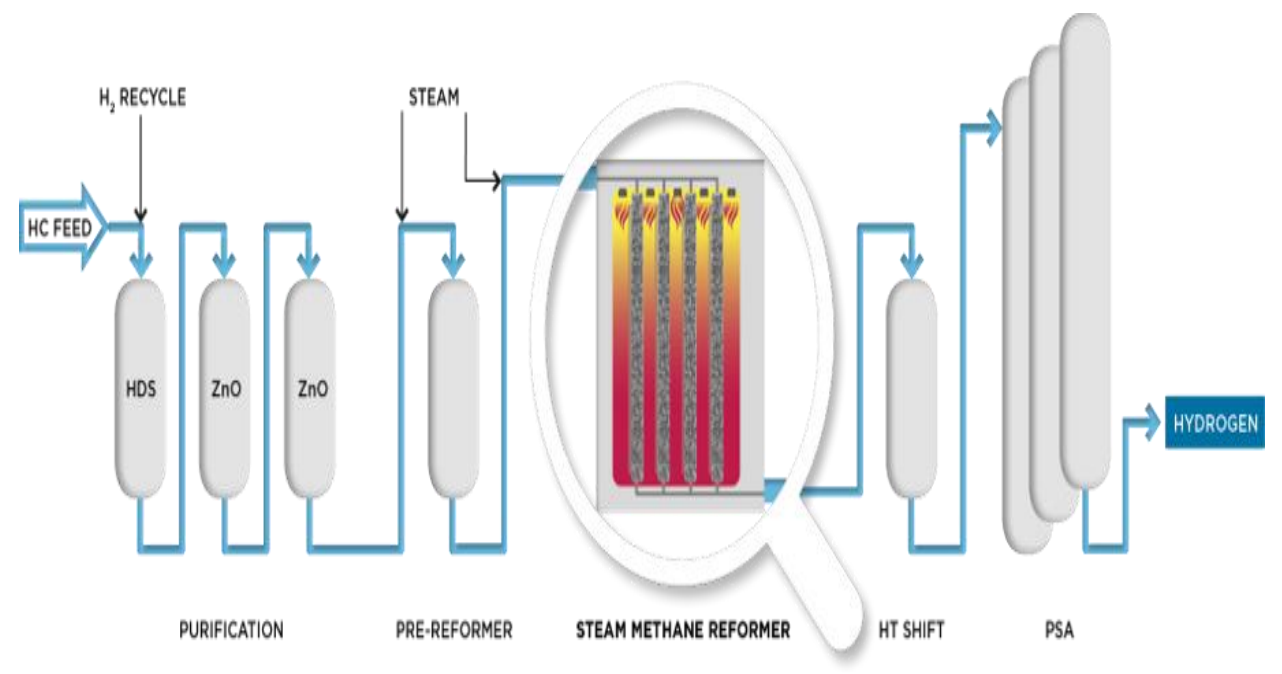

Figure 5 : MSR process schematic representation, Source: clariant.com

\subsection{Coal Gasification}

Coal gasification is a practice, through which $18 \%$ of the world's hydrogen production is achieved and shares basically the same principle as P.OX, in particular Coal reacts with pure oxygen in the presence of water vapor, from the reaction arises carbon monoxide, carbon dioxide, diatomic hydrogen and impurities. Subsequently, and after the impurities have been separated, carbon monoxide, through the Catalytic Shift Reaction, produces hydrogen and carbon dioxide. The Hydrogen is then separated.

Coal Gasification reaction :

$\mathrm{CH}_{0.8}+\mathrm{O}_{2}+\mathrm{H}_{2} \mathrm{O} \rightarrow \mathrm{CO}+\mathrm{CO}_{2}+\mathrm{H}_{2}+$ Coal Residue

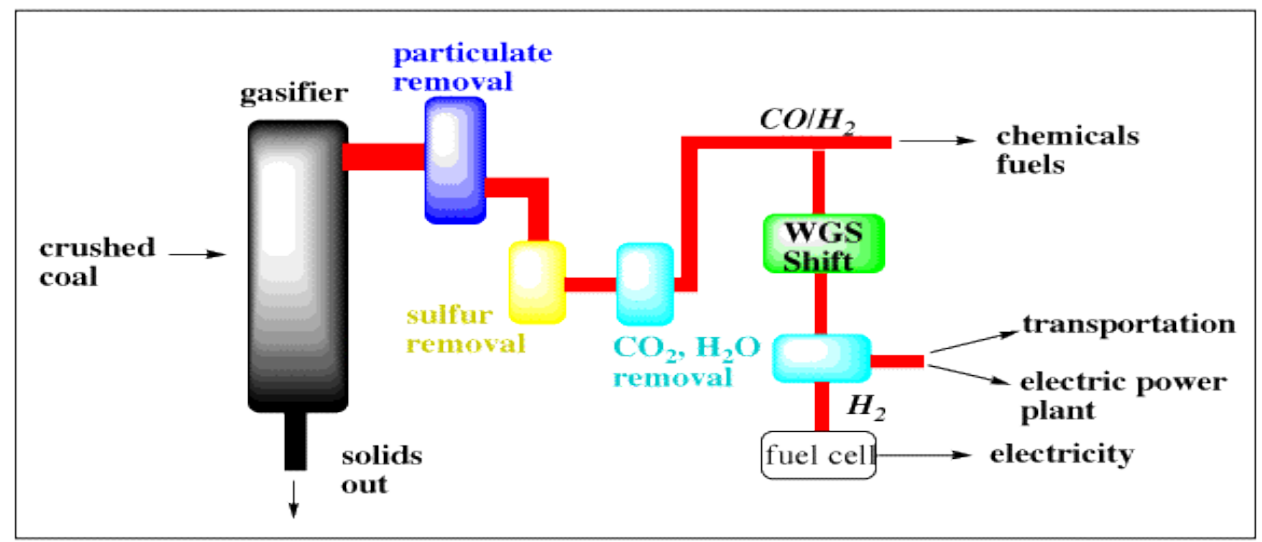

Figure 6 : Coal gasification process diagram, Source: butane.chem.uiuc.edu 


\subsection{Petroleum fraction partial oxidation}

P.OX is a hydrogen production method based on the oxidation of a particular type of hydrocarbon in the presence a controlled amount of oxidizing agent in the form of pure oxygen, so as to produce carbon monoxide and hydrogen, as opposed to complete oxidation that would correspondingly produce $\mathrm{CO}_{2}+\mathrm{H}_{2} \mathrm{O}$. The reaction takes place under very high pressure (typically between 1300-1800 psi). Hydrogen is produced by the catalytic shift reaction of $\mathrm{CO}[4]$ while any residual amount of Carbon Dioxide is absorbed via a basic solvent. This practice is responsible for producing $30 \%$ of the world's hydrogen production.

\section{Hydrogen Production - Partial Oxidation}

C. Process flow diagram of POX

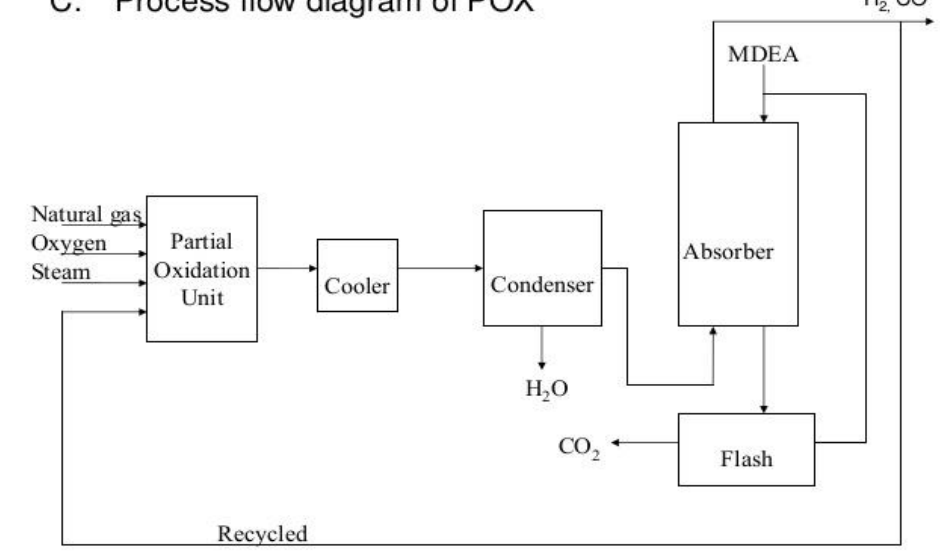

Figure 7 : POX flow diagram, Source: slideshare.net

\subsection{Alkaline Water Electrolysis}

Electrolysis of water is a well-known hydrogen production technology through the breakdown of water molecules into individual synthetics (hydrogen and oxygen). The devices that separate water by means of an electrical charge are electrochemical and consist of two electrodes(anode, cathode) and an external electrical circuit, connected the electrodes. The Water requires the addition of some chemical compound so that it becomes more electrically conductive and receptive to the process. The principle of operation of the device in question can be summarized as follows,

The water is enriched with an extra ingredient to make the water more conductive to electricity, most commonly, Sodium Chloride $(\mathrm{NaCl})$. The $\mathrm{NaCl}$, up-on contact with water, breaks down into sodium cations and chlorine anions. The external circuit through which the electrodes are connected is then excited by a DC source. The chlorine anions are oxidized on the anode, thus forming diatomic Chlorine gas that subsequently escapes from the mixture, the protons obtained as a result of Electrolysis[5] deposit their positive charge on the cathode, thus forming diatomic Hydrogen gas that also escapes from the mixture and is collected. Remaining in the mixture are hydroxyl anions and sodium cations which can be converted into caustic sodium in crystalline form by simply dehydrating the mixture.

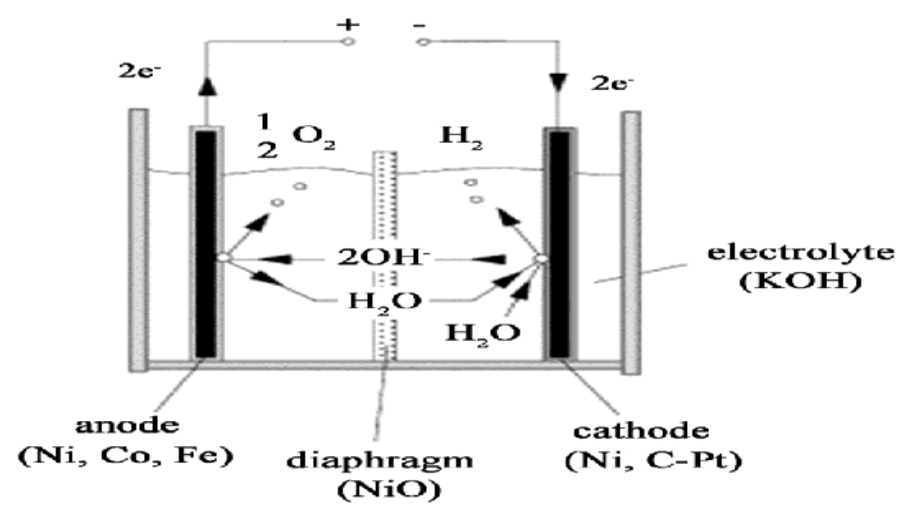

Figure 8 : AWE operating principle, Source: researchgate.net 


\subsection{Alternatives to Alkaline Water Electrolysis}

Conventional Alkaline Water Electrolysis is the simplest form of the process, alternatives to which are Polymer Electrolyte Membrane and High Temperature Electrolysis. PEM Electrolysers contains a solid polymer electrolyte (SPE) through which the protons reach the cathode, where they are reduced, thus forming Hydrogen Gas. The efficiency rate as compared to conventional AWE, is significantly higher, in particular 82-86\%[6] while maintaining operational status for high density of current. The HT Electrolysis process differs from the above, mainly in the electrolyte as it uses a ceramic, conductive material which allows for Oxygen ions to pass through it while Hydrogen gas is formed following the catalytic separation of steam inside the cell, to this day it is seen as a cost-ineffective power generation practice as compared to Diesel generators and other thermal machinery.
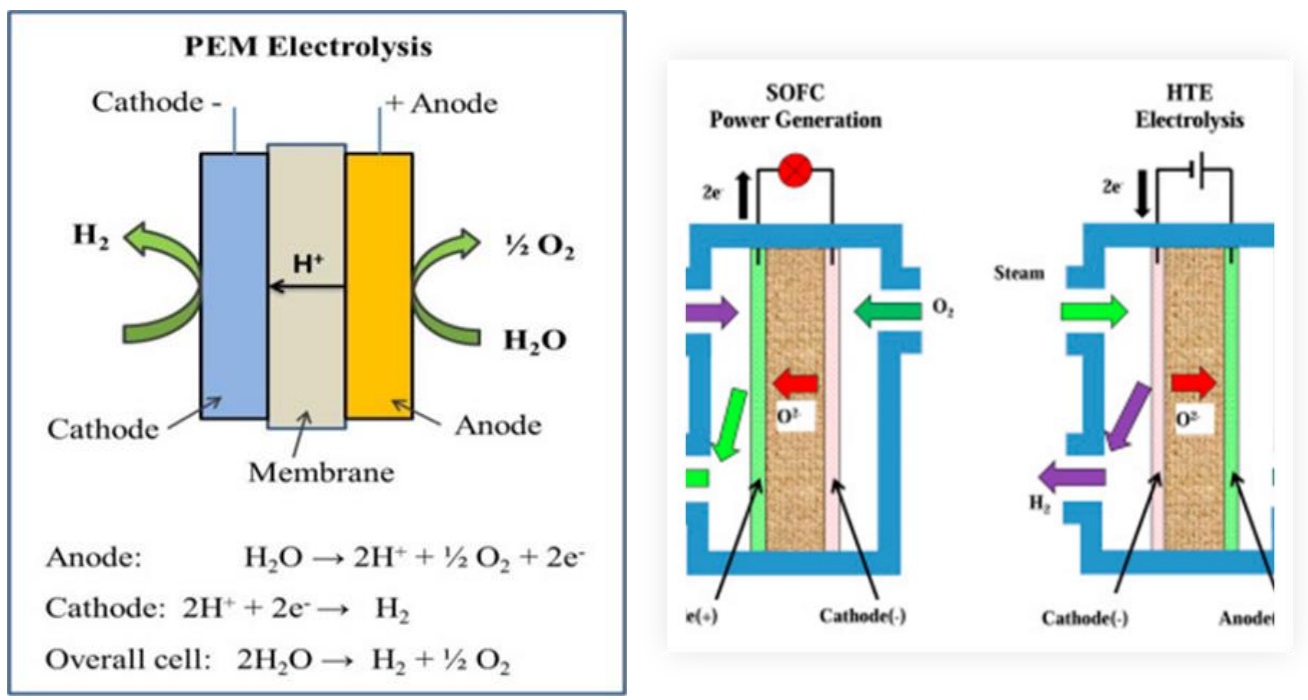

Figures 9,10 : Operating principle of PEM and HT-Solid Oxide Electrolysis processes, Source: sciencedirect.com

\subsection{Microbial Electrolysis Cells}

Organic waste is another source from which low-emission[6] Hydrogen production can occur combined with the fact that waste management is a vital area of industrial activity. The recovery of energy from wastewater is not a new technology, the scientific community has invested in the subject and there is power generating electrochemical technology based on the degradation of the organic fraction within the wastewater volume by specific microorganisms under anaerobic conditions, these devices are called Microbial Fuel Cells (MFC), however, a similar technology has also been developed for the production of hydrogen or methane (Microbial Electrolysis Cells). The device in question functions as follows.

* The waste volume is introduced into the anode chamber

* DC voltage is applied to the system

* Organic matter is oxidized by the bacteria In the anode chamber with the products being carbon dioxide and protons, among other impurities

* The protons penetrate the semipermeable membrane and when they eventually reach the cathode chamber, they are reduced and form hydrogen gas

Commonly used materials for electrodes are the following,

* Stainless steel

* Carbon-based composite

* Graphite

* Carbon cloth

Such technology cannot not be characterized as zero-emission as the production process involves carbon in the form of organic compounds, therefore although hydrogen, which can be a pure form of energy, is produced and while it is advantageous to apply renewable energy technologies, as a small amount of electrical power is required by the device, carbon dioxide emissions remain, in this context Carbon Capture and Storage systems can be implemented so that the environmental footprint of this technology is reduced to a minimum. 


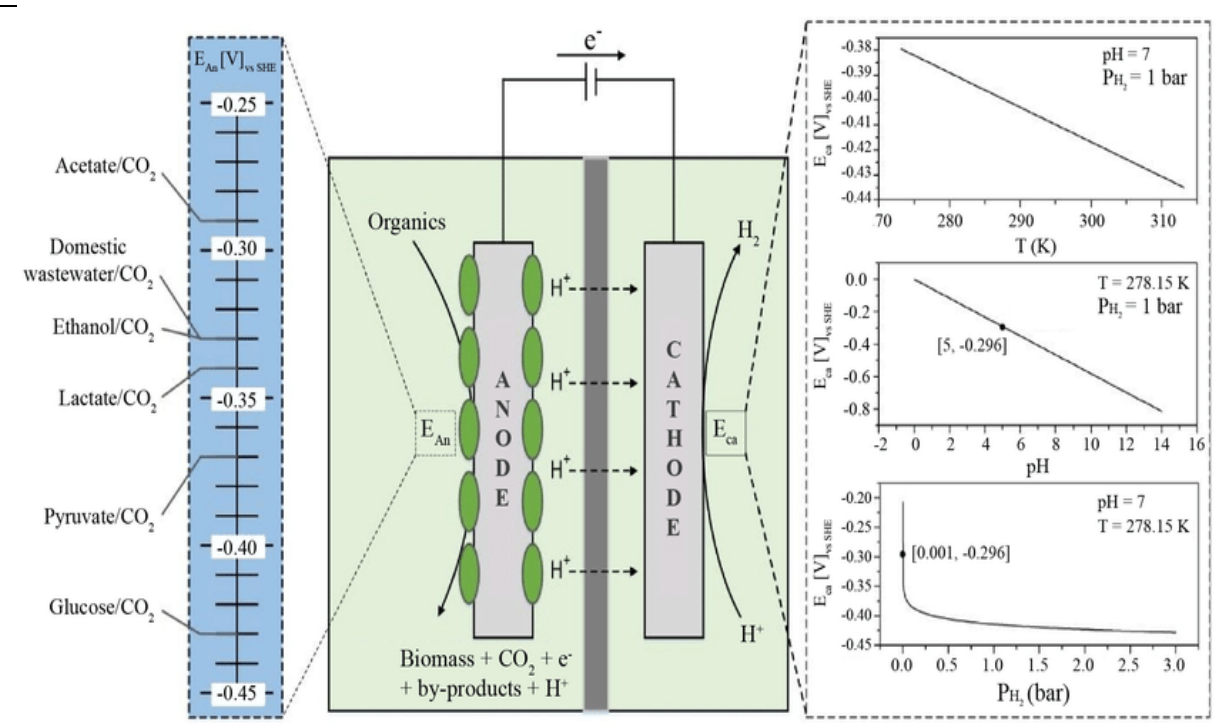

Figure 11 : Schematic representation of a Microbial Electrolysis Cell, Source: researchgate.net

\subsection{Polymer waste treatment}

Plastics can be directly converted to Hydrogen and Carbon Nanotubes through a process where polymer waste is shredded and mixed with various metal-oxides(Fe, $\mathrm{Al}$ ) that catalyze the -to be initiated- reaction[7], the mixture then is exposed to microwave radiation that results in carbon nanotubes and a gaseous fraction composed of $97 \%$ pure Hydrogen. The reasoning behind this process' success is the fact that polystyrene(often related to human cancer), polyethylene, polypropylene are not at all affected by the radiation which means that the catalysts are excited to the required degree.

Microwave--initiated catalytic scission

HDPE, PP and PS

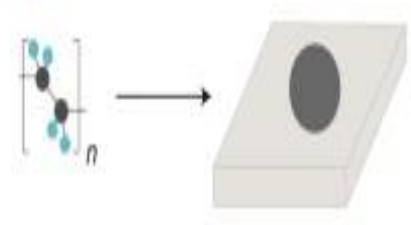

FeAlO, calalysts

\section{Intermediates converted to MWCNTs and hydrogen}

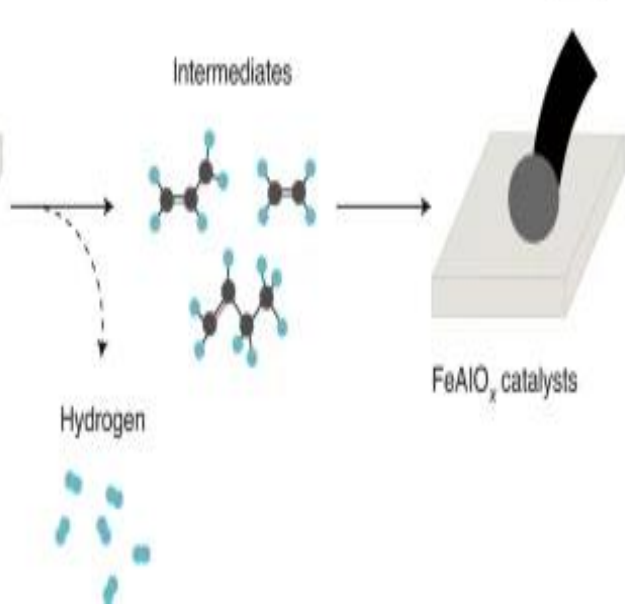

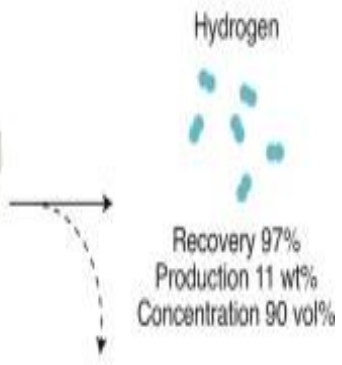

MWCNT production 30 w $\%$

Figure 12 : Direct conversion of Plastic waste to Hydrogen and MWCNT, Source: nature.com

\subsection{Other methodologies, currently in R\&D stage, Methane Pyrolysis}

Biomass is a renewable source of energy as it is closely associated to plant life-cycles and as such, it should be exploited to the furthest, in that respect, by thermally decomposing biomass, one can expect to receive an organics-rich aqueous phase as well as a much denser liquid fraction known as 'Bio-oil' [8]. As shown in [Image 13], both of the Pyrolysis products can be exploited for their energy production potential, specifically MEC [Image 11] can produce Hydrogen through the exerted aqueous phase while Hydrocarbon fuel-that can of course serve as the basis-fuel for a 'Blue Hydrogen' plant. Methane Pyrolysis along with Microwave direct conversion of plastics to Carbon nanotubes and Hydrogen[7] are some of the most promising new technologies for fighting Climate Change[6] and establishing a Circular Economy model on a global scale. 


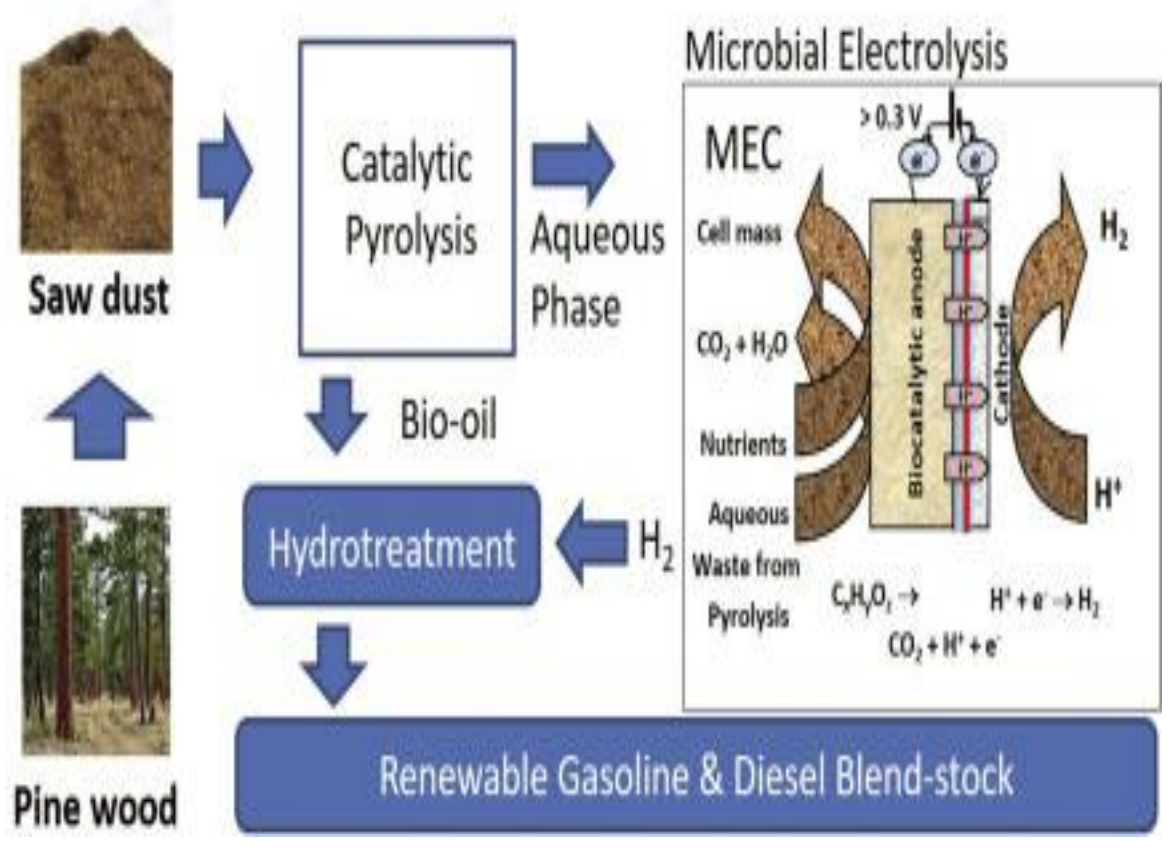

Figure 13 : Catalytic Methane Pyrolysis process, a diagram, Source: researchgate.net

- Plasma Electrolysis (Conventional AWE with extremely high voltage connected to the electrode circuit)

- Essentially an Electrolysis process taking place under extremely high Voltage as compared to - conventional AWE, HTE or PEM Electrolysis

- Produces Hydrogen on a much more efficient rate due to overall high temperature

- Can be further enhanced by enrichment of the electrolyte solution (acetic acid ex.)

○ Great potential in Future Hydrogen Production

○ Artificial Photosynthesis

\section{Hydrogen Storage}

Just a few years ago, not many people believed in the idea of an energy carrier-fuel that would, cost effectively, be in position -through the corresponding technology- to meet even a small fraction of the global energy demand, much less a source of energy that does not pollute up on exploitation and holds 4 times as much energy as conventional Hydrocarbons and over 140 times as much as the most efficient Li-Pol battery. Nowadays it is entirely possible and financially viable to produce Hydrogen[8] with minimal, if not zero, environmental footprint. Storing produced Hydrogen is an essential part of the Hydrogen Energy Autarky scheme and the current main storage practices are listed below.

\subsection{Physical Compression using electromechanical equipment}

* Expensive to store by Physical Compression until liquefication, as it needs to reach 5,000 psi in a conventional tank[15]

* Preventative maintenance of the pressure release mechanism[15] (valve) in conventional tanks to avoid thermal incidents

* Inefficient from a displacement standpoint as, given that 852L of $\mathrm{H}_{2}$ gas compress to approximately $1 \mathrm{~L}$ of liquid $\mathrm{H}_{2}$ [12], it would require quite a large tank in order for a significant amount of Energy to be stored

\subsection{Metal-Hydride Hydrogen compressors}

* Low pressure Hydrogen[12] is inserted to the metal-hydride powder filled cylinder[13-14]

* Cooling is applied while low-pressure $\mathrm{H}_{2}$ is being inserted[16]

* After the cylinder fills up, the cylinder is heated with a temperature differential of at least 303,3 K (As the $\Delta \mathrm{T}$ rises, so does the compression ratio)[15]

* Heating continues as high-pressure Hydrogen is exerted[10-12] 
* The Cylinder then cools down and the process is repeated

* High reliability rates as there are virtually no moving parts

* The Heat transfer fluid can be Water, SH Water, Oil, Steam etc.[10-14]

\subsection{Metal-Hydride tanks}

* Absorbtion of Hydrogen atoms as well as any impurities within the composite's spaces[14]

* Safe delivery of Hydrogen at a constant pressure value[12-16]

* The total amount of stored Hydrogen could account for 1\% - 7\%, depending on the thermal exposure

* Life expectancy is directly affected by the -to be stored- Hydrogen purity (Industrial Electrolysers produce with a $99.8 \%$ purity rate)

HYDROGEN CAN BE STORED

IN DIFFERENT FORMS

IN TANKS

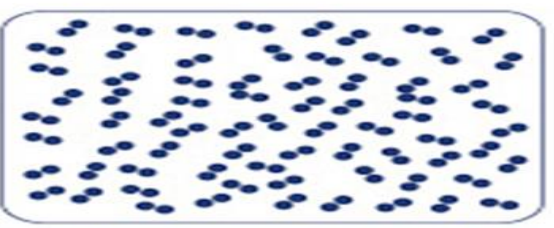

COMPRESSED GAS

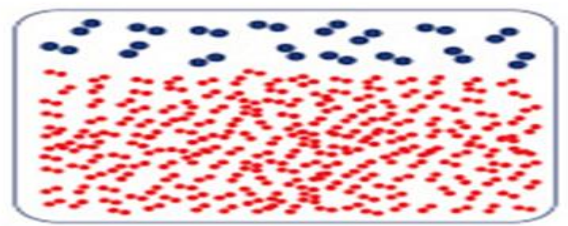

CRYOGENIC LIQUID

- Hydrogen Atom (H)

Hydrogen Molecule (H2)

Dydrogen Molecule (GAS)
IN MATERIALS

Increasing Density

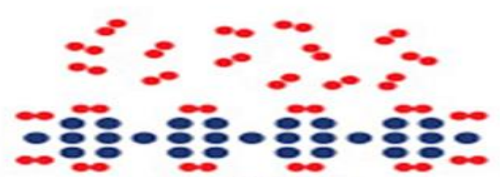

SURFACE

ADSORPTION
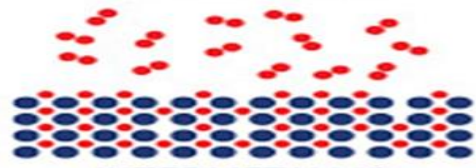

INTERMETALLIC

HYDRIDE

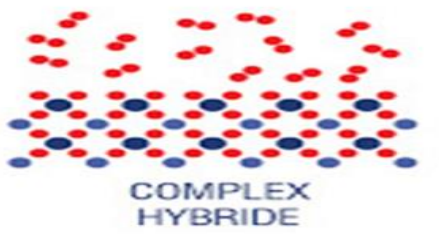

Figure 14 : Hydrogen storage pathways, Source: hydroville.be

\subsection{In-compound storage}

Hydrogen can also be stored in Ammonia due to the fact that 3 Hydrogen atoms are binded to each Ammonia molecule.

\section{Hydrogen Utilization}

Hydrogen can be utilized either electrochemically or thermochemically, The corresponding technologies are shown-explained below,

\subsection{Hydrogen Fuel Cell}

Hydrogen fuel cells[20] are electrochemical devices that exploit a series of chemical reactions to generate electricity. Fuel cells operate on hydrogen and oxygen (supplied as a component of air). The 1990s were marked as the first period when mass production and widespread utilization of the fuel cell began. It was also important to mention that the global capacity for electricity produced from fuel cells is estimated to be between $1 \mathrm{GW}$ and $2 \mathrm{GW}$. A conventional fuel cell contains an electrolyte and two electrodes. The electrolyte acts as a semipermeable membrane that allows the passage of positively charged atoms(such as protons). Diatomic hydrogen is characterized by a neutral charge, therefore, in order to penetrate the membrane, the catalyst acts in order to separate the electron from the proton $(\mathrm{H}+)$. Protons are now able to penetrate the electrolyte, however, in order to react with oxygen, the electrons detached from the individual hydrogen atoms must be transported to the cathode chamber, the transfer is completed by means of connecting an 


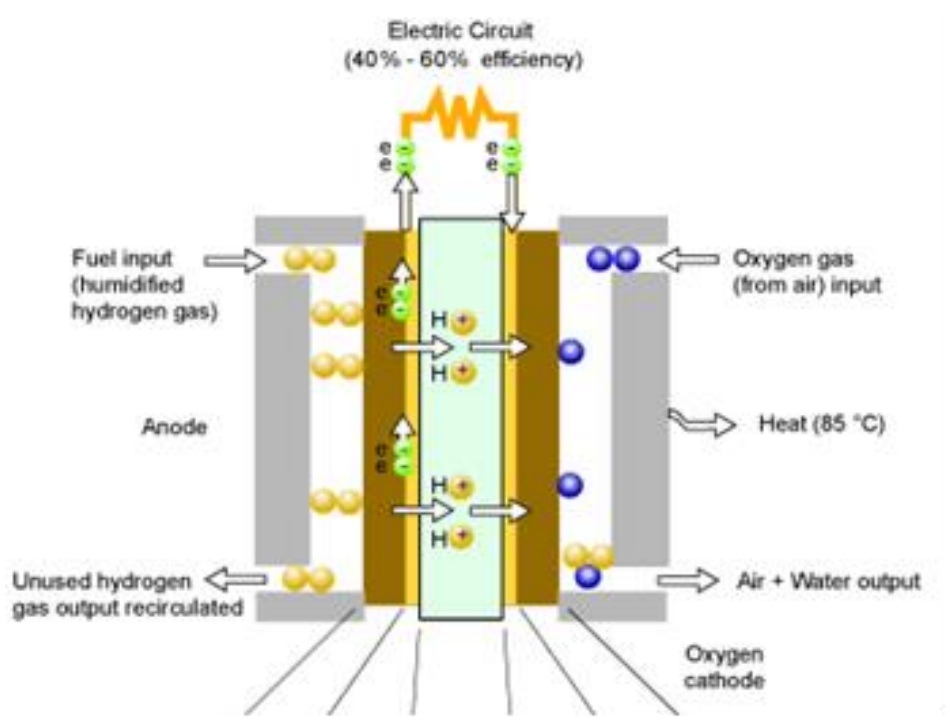

Figure 15 : PEM Hydrogen Fuel cell principle of operation, Source: ctc-n.org

We can summarize the FC operation principle as shown below,

* Catalytic separation of the proton and electron that compose a Hydrogen molecule

* Power generation due to the electrons moving to the cathode chamber via the external circuit (energy loss in the form of heat)

* Protons penetrate the membrane due to their positive charge

* Reaction between Oxygen(air-provided) and Hydrogen (protons merge with electrons once again) to produce water

It is easy to see that hydrogen fuel cells are capable of powering any electricity-supplied system, be it a household appliance, a heating system, or use in the various energy-intensive applications of individual or industrial activities (Transportation, Metallurgy eg.).

\subsection{Fuel Cell options}

Electrochemical cells that produce electrical power through hydrogen vary according to their manufacturing characteristics though they all share basically the same principle shown above. When considering small-scale, household applications, Alkaline Fuel Cells are the most suitable as they generally have a power output of about $300 \mathrm{~W}$ to $5 \mathrm{~kW}$ while operating under $70 \%$ efficiency. AFC contain a liquid phase electrolyte that commonly consists of Potassium Hydroxide and Water, meaning that there is always a risk of leakage, such cells typically project an operating Temperature of $150-200^{\circ} \mathrm{C}$ and require Hydrogen of exceptionally high purity as well as a platinum catalyst. When referring to energy demands of over 50 $\mathrm{kW}$, two FC technology variations are currently in position to come through, Proton Exchange Membrane and Phosphoric Acid Fuel Cells. PA FC contains a Phosphoric acid, liquid state electrolyte and can produce up to $200 \mathrm{~kW}$ on an efficiency rate of $40-80 \%$, their operating Temperature fluctuates between $150-200{ }^{\circ} \mathrm{C}$ though they can tolerate as high as $1.5 \%$ of CO. One of the most significant drawbacks of such cells is the fact that they require stainless internal components due to the corrosive properties of the electrolyte. On the other hand, PEM FC use a semi-permeable membrane(polymer) electrolyte and have a typical power output range of $50-250 \mathrm{Kw}$ on an efficiency rate of $40-50 \%$. A PEM FC operates at $80^{\circ} \mathrm{C}$ which makes it suitable for household applications and means of transportation[22]. The final variation of Hydrogen-fueled Electrochemical Cells is the Solid Oxide Fuel Cell. SO FC typically contain a Zirconium or Calcium oxidebased electrolyte[16-18], produce up to $100 \mathrm{~kW}$ of electrical power on $60 \%$ efficiency. The main deficiency of this particular cell is it's large size which, combined with the corresponding extremely high operating Temperature of about $1000{ }^{\circ} \mathrm{C}$, significantly limits it's field of application.

\subsection{Hydrogen Internal Combustion Engine}

The excessive use of hydrocarbon internal combustion-gasification technology for the bulk of industrial applications over the last three centuries, almost exclusively, bears responsibility for the impending Climate Change as The Greenhouse Effect has become a global issue in recent decades. Technology that produces mechanical power-useful work through exploiting an expanding gaseous mixture is one of the most important technological breakthroughs and it is possible for it to continue to be widely implemented, with the prerequisite of drastic reduction and eventual annihilation of emissions of gaseous pollutants. 
In this context, Hydrogen can replace Hydrocarbons and meet the requirements of each application without producing $\mathrm{CO}_{2}$ as it ignites(if supplied with pure Oxygen)[19-20]. It is a fact, however, that the HICE Powertrain (Hydrogen Internal Combustion Engine) differs compared to a conventional diesel or petrol IC powertrain. There are commercially available models of such engines[21] and the imminent imposition of fines for the owners of machinery or means of transportation that produce Greenhouse gas emissions makes the internal combustion of hydrocarbons an extremely short-term, non-viable solution, especially as technological development allows cost-competitive mass production of hydrogen[22], which is directly usable and able to meet energy needs without polluting the environment.

\subsubsection{Current challenges}

* Fuel Cell technology has a higher efficiency rate[21] (almost twice as efficient)

* Hydrogen fuel tank generally occupies a significant amount of storage space in vehicles

* Nitrogen oxides are still emitted onto the atmosphere due to the air provided Oxygen[23]

* Victim to the current demonizing of the Internal Combustion Engine

* Hydrogen occupies approximately $40 \%$ of the combustion chamber volume[24], thus producing significantly less power than an equivalent gasoline ICE

* Potential water leakage from the combustion chamber could result in the attenuation of the engine oil lubricating properties[23-24]

* Positive Crank Ventilation-Spark Ignition technology is absolutely necessary

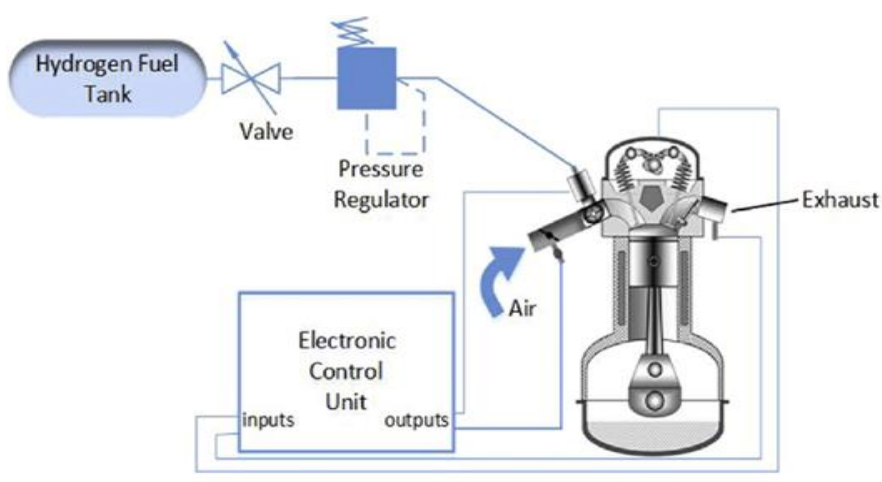

ICE

Figure 16 : Hydrogen Internal Combustion Powertrain, Source: researchgate.net

\section{References}

1. F. Mueller-Langera,*, E. Tzimas, M. Kaltschmitta, S. Petevesb, Techno-economic assessment of hydrogen production processes for the hydrogen economy for the short and medium term, 2007.

1) Institute for Energy and Environment gGmbH, Torgauer Str. 116, 04347 Leipzig, Germany

2) European Commission, DG Joint Research Centre, Institute for Energy, P.O. Box 2, 1755 ZG Petten, The Netherlands

2. Keith Scott, Electrochemical Methods for Hydrogen Production, Edited by Keith Scott, 2020. Introduction to Electrolysis, Electrolysers and Hydrogen Production

Newcastle University, UK

3. Yongliang Yan1, Dhinesh Thanganadar1, Peter T. Clough*, Sanjay Mukherjee, Kumar Patchigolla, Vasilije Manovic, Edward J. Anthony, 'Process simulations of blue hydrogen production by upgraded sorption-enhanced steam methane reforming (SE-SMR) processes', 2020.

Energy and Power Theme, School of Water, Energy and Environment, Cranfield University, Cranfield, Bedfordshire MK43 OAL, UK

4. Marcus Newborough, Graham Cooley, Developments in the global hydrogen market: The spectrum of hydrogen colours, ITM Power Plc, Sheffield, UK, 2020.

5. G.E. Marnellos, C. Athanasiou, S.S. Makridis and E.S. Kikkinides, Invited chapter "Integration of Hydrogen Energy Technologies in Autonomous Power Systems", Book: Hydrogen-based Autonomous Power Systems, Techno-economic Analysis of the Integration of Hydrogen in Autonomous Power Systems, Series: Power Systems, by Lymberopoulos, Nikolas 
\& Zoulias, Emmanuel I. (Ed.), 2008, Approx. 190 p. 50 illus., Hardcover, ISBN: 978-1-84800-246-3, Springer-Verlag (London) Ltd, 2008.

6. Stavros Lazarou, Vasiliki Vita, Maria Diamantaki, Diotima Karanikolou-Karra, George Fragoyiannis, Sofoklis Makridis, Lambros Ekonomou, "A simulated roadmap of hydrogen technology contribution to climate change mitigation based on Representative Concentration Pathways considerations”, Energy Science \& Engineering, Wiley, 2018.

7. A.Escapa a ,n, R.Mateos ${ }^{\text {a }}$, E.J.Martínez a, J.Blanes ${ }^{\text {b }}$, Microbial electrolysis cells: An emerging technology for wastewater treatment and energy recovery. From laboratory to pilot plant and beyond, Renewable and Sustainable Energy Reviews, 2015.

a) Chemical and Environmental Bioprocess Engineering Department, Natural Resources Institute (IRENA), Universidad de León, Av. de Portugal 41, 24071 León,

b) Department of Electrical Engineering and Automatic Systems, University of León, Campus de Vegazana s/n, 24071 León, Spain

8. Xiangyu Jie, Weisong Li, Daniel Slocombe, Yige Gao, Ira Banerjee, Sergio Gonzalez-Cortes, Benzhen Yao, Hamid AlMegren, Saeed Alshihri, Jonathan Dilworth, John Thomas, Tiancun Xiao \& Peter Edwards, Microwave-initiated catalytic deconstruction of plastic waste into hydrogen and high-value carbons, Nature Catalysis, 2015.

9. Stefan Schneider[1],*, Siegfried Bajohr[1], Frank Graf[1,2], Thomas Kolb[1,2], 'State of the Art of Hydrogen Production via Pyrolysis of Natural Gas' ChemBioEng Rev 2020, 7, No. 5, 150-158, 2020.

10. S.S. Makridis, Chapter 1: Hydrogen absorption for storage and compression in Book: Methane and Hydrogen for Energy Storage, Invited chapter by Senior Editor for Power \& Energy with the Institution of Engineering \& Technology (IET), edited by R. Carriveau \& D.S-K. Ting, Turbulence \& Energy Laboratory, University of Windsor, Canada 2016.

11. Evangelos Gkanas, Alina Damian, Alexandra Ioannidou, George Stoian, Nicoleta Lupu, Margarit Gjoka, Sofoklis Makridis, "Synthesis, Characterisation and Hydrogen Sorption Properties of Mechanically Alloyed Mg(Ni1-xMnx)2", MATERIALS TODAY ENERGY - Q1, ELSEVIER, Volume 13, September 2019, Pages 186-194, 2019

12. A Ioannidou, SS Makridis $\dagger$, M Gjoka, EI Gkanas, AK Stubos, N Lupu, D Niarchos, "Structure, microstructure and hydrogen storage properties of melt-spun V55Ti21 Cr17Fe7 and V55Ti21Mn17Fe7", Materials, MDPI, accepted to be published, in press, in press, 2019.

13. Giannakis, T.; Ioannidou, A.; Niarchos, D.; Karyofyllis, K.; Saltas, M.; Makridis, S.S., «One-Step Synthesis and Sintering of Skutterudite CoSb3: Smart Houses Materials?». Materials, MDPI, 2019.

14. JM Barandiaran, A Martin-Cid, AM Schönhöbel, JS Garitaonandia, M Gjoka, D Niarchos, SS Makridis, A Pasko, A Aubert, F Mazaleyrat, G Hadjipanayis, "Nitrogenation and sintering of (Nd-Zr) Fe10Si2 tetragonal compounds for permanent magnets applications", Journal of Alloys and Compounds, Volume 784, Pages 996-1002, 2019.

15. Kamel Idris-Bey, Pierre Bénard, Sofoklis Makridis, "Complete Modeling of the Hydrogen Stored in a Spherical Cavity", Advances in Science, Technology and Engineering Systems, Scopus Indexed, 3(4), 122-129, 2018.

16. A. Ioannidou, S.S. Makridis, E.S. Kikkinides, A.K. Stubos, M. Gjoka, "Morphology, Microchemistry, Structural and Hydrogenation Characteristics of (Zr-Ti)(Cr-V-Ni) 2 Intermetallic Compounds", J Nanosci Adv Tech 1 (2), 17-29, 2015.

17. E.I. Gkanas, S.S. Makridis, "Thermal Management of a $\mathrm{MgH}_{2}$ cylindrical tank including the thermal coupling with an operating SOFC during the dehydrogenation process", International Journal of Hydrogen Energy, 2016.

18. Evangelos I Gkanas, Martin Khzouz, Grigorios Panagakos, Thomas Statheros, Panagiota Mihalakakou, Gerasimos Siasios, Georgios Skodras, Sofoklis S Makridis, "Hydrogenation behavior in rectangular metal hydride tanks under effective heat management processes for green building applications", Energy, Volume 142, Pages 518-530, 2018.

19. Stavros Lazarou, Sofoklis Makridis*, "Hydrogen Storage Technologies for Smart Grids applications", Review Article, Invited Paper, Challenges, 8(1), 13; MDPI, 2017.

20. Saddam Hussain ${ }^{1}$ - Li Yangping ${ }^{1}$, 'Review of solid oxide fuel cell materials: cathode, anode,and electrolyte', Energy Transitions, 2020.

21. Andre Lanz, P. Eng., James Heffel, Colin Messer, 'Hydrogen Fuel Cell Engines and Related Technologies: Rev 0', December 2001,

Module 3: Hydrogen use in internal combustion engines (2001)

College of the Desert, Palm Desert, CA, USA, Energy Technology Training Center, College of the Desert, 43-500 Monterey Avenue, Palm Desert, CA 9226

22. Evangelos Ch Tsirogiannis, Georgios E Stavroulakis, Sofoklis S Makridis, Electric Car Chassis for Shell Eco Marathon Competition: Design, Modelling and Finite Element Analysis, World Electric Vehicle Journal, Scopus indexed, 2019, 10(1), 8;, 2019.

23. R. Sivabalakrishnan and C. Jegadheesan, 'Study of Knocking Effect in Compression Ignition Engine with Hydrogen as a Secondary Fuel', 2014.

1) Department of Mechatronics, SNS College of Technology, Coimbatore, India

2) Department of Mechatronics, Kongu Engineering College, Perundurai, Erode, India 
24. Abel Rouboa,, 1,2 Valter Silva, and Nuno Couto, 'Exergy Analysis in Hydrogen-Air Detonation', 2012.

1) CITAB/Engineering Department, School of Science and Technology of University of UTAD, Vila Real 5001-801, Portugal

2)MEAM Department, University of Pennsylvania, Philadelphia, PA 19104, USA 